FACULDADE DE CIÊ NCIAS ECONÔ MICAS DA UFRGS

REESTRUTURAÇÁ O DA PRODUÇÁ O AGRICOLA NO RIO GRANDE DO SUL, DE 1970 A 1996 E UMA ESTIMAÇȦ O PARA 2012 TIAGO WICKSTROM ALVES

A CRIMINALIDADE NA RECIAO METROPOLTANA DE SALVADOR JOSÉ CARRERA FERNANDEZ, LUIZ FERNANDO LOBO

COMPEIITIVIDADE INTERNACIONAL EM SOFTWARE: UM ESTUDO SOBRE A EXPERIÊNCIA DE FLORIANÓ POLIS HOVÉDO NUNES LINS

MODELOS DE ORGANIZAÇẢ O E REPARTIÇẢ O DE RENDAS NA CADEIA PRODUTIVA DO GÁS NATURAL.

HELder QUEIROZ PINTO Jú NIOR, RODOLFO TORRES dOS SANTOS

REGIMES MONETÁ RIOS E DIVIDA PÚ BLICA: UMA ANÁ LISE DE MECANISMOS ALTERNATIVOS DE COORDENAÇÃO MACROECONÓ MICA

manoel Carlos de Castro Pires

ECONOMIA DOS RECURSOS NATURAIS E SEUS INDICADORES DE ESCASSEZ: UMA QUESTÃ O DE SUSTENTABILIDADE ANDREA SALES SOARES DE AZEVEDO MELO

O ECOPROTECIONISMO AGRICOLA NA UNIĀ O EUROPEIA E SEUS POSSIVEIS IMPACTOS SOBRE A ECONOMIA BRASILEIRA Rodrigo daniel Feix, Clá udio R. Fóffano Vasconcelos

PADRÓ ES DE DESENVOLVIMENTO, FUNÇ Ó ES ESTATAIS E ENDIVIDAMENTO NO CAPITALISMO CONTEMPORÁNEO paulo Balanco, Eduardo Costa Pinto

A INTERNACIONALIZAÇÃO DO VAREJO A PARTIR DOS CASOS WAL-MART E CARREFOUR

Armando joảo dalla Costa

UMA ANÁ LISE ECONOMÉTRICA DO FUTEBOL BRASILEIRO ARI Francisco de Araujo JR, Clá udio D. SHIKIDA, LEONARDO M. MONASTERIO

O BRASIL E A ECONOMIA INTERNACIONAL: RECUPERAÇÃ O E DEFESA DA AUTONOMIA NACIONAL

RESENHA DE ALEXANDRE CÉ SAR CUNHA LEITE

REGIMES MONETÁ RIOS: TEORIA E A EXPERIÊNCIA DO REAL ResenHa de Fernando Ferrari Filho

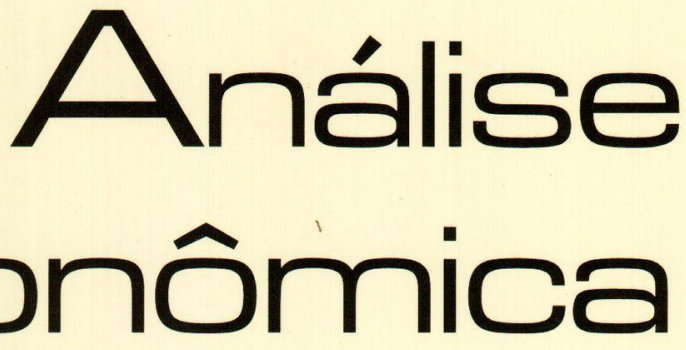


Universidade Federai. do Rio Grande do Sul Reitor: Prof José Carlos Ferraz Hemnemann

Facul dade de Cuéncias Economicas

Diretor: Prof. Gentil Corazza

Ceniro de Estudos f Prequisas Economicas

Diretor: Prof. Lovois de Andrade Miguel

Depariamenio de Crências Economicas

Chefe: Prof Ricardo Dathein

Departamento de Cîncias Coniábeis f A tuaria Chefe: Prof. Ceno Odilo Kops

Curso de Pós-Graduaçó em Economia

Coordenador: Prof. Fernando Ferrari Filho

Curso de Pos-Grainaça em Desenvolvimento RuRAI

Coordenador: Prof. Paulo Dabdab Waquil

Conseluo Eni tokial: André Moreira Cunha (UFRGS) Carlos G. A. Mielitz Netto (UFRGS), Carlos Henrique Hom (UFRGS). Eduardo A. Maldonado Filho (UFRGS). Eleutério F S. Prado (USP), Eugênio Lagemann (UFRGS), Fernando Cardim de Carvalho (UFRJ). Femando Ferrari Filho (UFRGS), Fernando de Holanda Barbosa (FGV/RJ), Flávio Augusto Ziegelmann (UFRGS), Flávio Vasconcellos Comin (UFRGS), Gentil Corazza (UFRGS), Giácomo Balbinot to Neto (UFRGS), Gustavo Franco (PUC/RJ) Hélio Henkin (UFRGS), Jan A. Kregel (UNCTAD), João Rogério Sanson (UFSC), Joaquim Pinto de Andrade (UnB), Júlio César Oliveira (UFRGS), Luiz Estrella Faria (UFRGS), Luiz Paulo Ferreira Nogueról (UFRGS), Marcelo S Portugal (UFRGS), Maria Alice Lahorgue (UFRGS), Octávio Augusto Camargo Conceicão (UFRGS), Paul Davidson (University of Tennessee), Paulo D. Waquil (UFRGS), Pedro C. D. Fonseca (UFRGS), Philip Arestis (University of Cambridge), Ricardo Dathein (UFRGS) Ronald Otto Hillbrecht (UFRGS), Sabino da Silva Porto Jr (UFRGS), Sérgio M. M. Monteiro (UFRGS), Stefano Florissi (UFRGS) e Werner Baer (University of IIIinois at Urbana - Champaign)

Comissão Emroniai: Eduardo Augusto Maldonado Filho, Fernando Ferrari Filho, Hélio Henkin. Marcelo Savino Portugal, Paulo Dabdab Waquil e Sérgio Marley Modesto Monteiro.

EnIrok: Sérgio Marley Modesto Monteiro

Ediror Adjun ro: Hélio Henkin

Secretário: Emerson Douglas Neves

REVISÃo DE IEX ros: Vanete Ricacheski

Emioração: Núcleo de Editoração e Criação da

Gráfica da UFRGS - Janaína Horn e Junia Saedt

Fundador: Prof Antonio Carlos Santos Rosa
Os materiais publicados na revista Análise Econômica são da exclusiva responsabilidade dos autores. É permitida a reprodução total ou parcial dos trabalhos, desde que seja citada a fonte. Aceita-se permuta com revistas congêneres. Aceitam-se, também, livros para divulgacão, elaboraça de resenhas e recensões Toda correspondência: material para publicação (vide normas na terceira capa), assinaturas e permutas devem ser dirigidos ao seguinte destinatário:

Prof. Sérgio Marley Modesto Monteiro Revista Andilse Económica - Av. João Pessoa, 52 CEP 90040-000 PORTO ALEGRE - RS, BRASIL Telefones: (051) $33163513 / 33164164$

Fax: (051) 33163990 - E-mail: rae@vortex ufrgs.br

A Revista Análise Econômica agradece a colaboração dos pareceristas do número 43, abaixo relacionados:

Adalmir Antonio Marquetti

André Moreira Cunha

Carlos José Caetano Bacha

Carlos Mielitz. Netto

Clailton Ataídes de Freitas

Claudio Roberto Fóffano Vasconcelos

Eduardo Ernesto Filippi

Eduardo Pontual Ribeiro

Eleuterio Fernando da Silva Prado

Fernando J Cardim de Carvalho

Fernando Augusto Mansor de Mattos

Fernando Ferrari Filho

Flávio Tosi Feijó

Flavio Vilela Vieira

Francisco Paulo Cipolla

Gentil Corazza

Gíacomo Balbinotto Neto

Helio Henkin

Jefferson Andronio Ramundo Staduto

João de Deus Sicsú Siqueira

José Carrera Fernandes

Leonardo Monteiro Monasterio

Luís Fernando de Paula

Luis Roberto Nascimento

Manoel Carlos de Castro Pires

Octavio Augusto Camargo Conceição

Patrízia Raggi Abdallah

Robson Antonio Grassi

Ronald Otto Hilbrech

Tiago Wickstrom Alves

Tito Belchior Silva Moreira

Análise Econônica

Ano 23, n ${ }^{\circ} 44$, setembro, 2005 - Porto Alegre

Faculdade de Ciências Economicas, UFRGS, 2000

Periodicidade semestral, março e setembro

1. Teoria Econômica - Desenvolvimento Regional -

Economia Agrícola - Pesquisa Teórica e Aplicada -

Periódicos. I.. Brasil

Faculdade de Ciências Econômicas,

Universidade Federal do Rio Grande do SuI

CDD 330.05

CDU $33(81)(05)$ 


\title{
Uma análise econométrica do futebol brasileiro
}

\author{
Ari Francisco de Araujo Jr.* \\ Cláudio D. Shikida* \\ Leonardo M. Monasterio"*
}

\begin{abstract}
Resumo: Neste artigo apresentamos uma análise "esportométrica" do desempenho dos times de futebol participantes de um dos mais importantes torneios do gênero no mundo: o Campeonato Brasileiro (1971-1998). Postula-se que o bom desempenho dos times seja relacionado não apenas à qualidade de seus jogadores como também a fatores econômicos e políticos. Duas classes de modelos principais são estimados sob definições alternativas da variável dependente ("sucesso do time no campeonato"): pooled logit model e fixed effects logit model. Os resultados mostram que a chance de se estar nos primeiros lugares do ranking do campeonato apresenta uma relação positiva com respeito à eficiência do time em termos de artilharia. Além disso, estados mais ricos possuem maior chance de apresentar times nas primeiras colocações do campeonato, embora este efeito seja decrescente. Finalmente, existem evidências de que, pelo menos no curto prazo, a politica exerce influência positiva sobre os resultados estaduais obtidos no Campeonato Brasileiro de Futebol. Além disso, os resultados sugerem que no longo prazo o processo político reduz a chance de o estado colocar uma equipe entre as melhores do campeonato brasileiro de futebol.
\end{abstract}

Palavras-chave: Esportometria, Futebol, Economia e Esportes.

Abstract: This paper reports regression results identifying the variables influencing a state's performance in Brazilian Soccer's Championship. The results reveal that economic, club-specific controls and political factors are important. An inverted U-shaped relationship is found with respect to regional per capita wealth. We also found significant positive political effects with respect to the performance of Brazilian teams in the short run and negative in the long run. Explanations for our results are offered.

Keywords: Sportometrics, Soccer, Economics and Sports.

JEL - Classification: L80, L83.

• Professores do IBMEC-MG. Respectivamente: arifaj@ibmecmg.br e claudiods@ibmecmg.br.

" Professor do Curso de Economia, UFPel (leonardo.monasterio@gmail.com).

Uma primeira versão deste artigo recebeu excelentes críticas e comentários e sugestōes de João Ricardo Faria (The University of Texas at Dallas), William Summerhill (UCLA), Gilson Geraldino da Silva Jr. (IBMEC-MG) e Cristiano Machado Costa e de referees anônimos. Agradecemos também a Marcus R. S. Xavier (IBMEC-MG) pela indicação do survey da revista The Economist. Por fim, somos gratos a Martin Dietrich Brauch pela cuidadosa revisão e pelos comentários. Os eventuais erros remanescentes são de inteira responsabilidade dos autores. 


\section{Introdução}

No Brasil, tal como em outros países do mundo, as conversas de segunda-feira giram em torno dos resultados do futebol. Contudo, a influência do esporte vai bem mais longe e está bastante relacionada como a vida política da nação. Os resultados obtidos pela seleção brasileira foram considerados importantes para o apoio popular aos governos militares nos anos 1970 e os ditadores, por vezes, participavam pessoalmente na escolha dos jogadores. Mesmo depois da redemocratização, os resultados obtidos em campo são considerados relevantes para as reeleições dos governantes, e ex-jogadores bem-sucedidos têm carreira garantida como políticos. ${ }^{1}$

Apesar dessa importância, a análise econômica do futebol é praticamente desconhecida no Brasil. As razões para isso fogem ao alcance deste trabalho, mas podem estar relacionadas com uma concepção que este paper quer questionar. Brasileiros, em geral, vêem o esporte como desprovido de quaisquer leis e tendências. Por considerarem o que acontece em campo como mágico ou sublime (especialmente quando seus times ganham) ou ao puro azar (quando seus times perdem), brasileiros tendem a considerar que o esporte não é suscetível a uma análise fria e científica.

O presente trabalho critica essa visão oferecendo uma abordagem econômica ao assunto. Tal visão se justifica, por exemplo, quando se pensa nos elevados valores envolvidos no mercado dos jogadores de futebol, ${ }^{2}$ uma característica que, pelo menos no (autoproclamado) país do futebol, já foi até alvo de investigações parlamentares. Os comportamentos lícitos e ilícitos, dentro e fora de campo, não são estranhos para a Ciência Econômica. O comportamento de dirigentes de futebol, jogadores e técnicos mostra evidências de racionalidade econômica, e as diferenças entre um jogador e um empresário talvez sejam menores do que os apaixonados torcedores brasileiros supõem. Mesmo com os desempenhos variando de acordo com os talentos individuais, é evidente que ambos respondem a incentivos monetários. Metaforicamente, o homo economicus vai ao estádio de futebol também no Brasil.

\footnotetext{
1 Ver Bellos (2002) para uma interessante análise sociológica do futebol no Brasil.

${ }^{2}$ Segundo Unzelte (2002), em 2001, o valor de mercado do clube alemăo Bayern era de US\$ 692,5 milhões. Próximo a este valor (US $\$ 650$ milhões) seria o valor do investimento em jogadores feito pelos clubes italianos da primeira divisão. Goere e Minkman (1996) fazem observaçōes similares sobre o futebol holandês. No survey da The Economist sobre o tema, Stefan Syzmanski estima que a indústria mundial do futebol movimente aproximadamente U\$ 216 bilhões.
} 


\section{Um panorama da literatura e objetivos}

Rosen e Sanderson (2000) afirmam que o primeiro trabalho sobre Economia dos Esportes é o de Rottenberg (1956). Desde então a pesquisa na área se expandiu em profundidade e abrangência, já tendo se consolidado. O periódico sobre o tema, o Journal of Sports Economics, começou a ser publicado faz cinco anos e já há um volume da prestigiosa série da Elgar Reference Collection (Zimbalist, 2001). Bons resumos sobre a variedade de pesquisas possíveis nesta área encontram-se em Tollison (2002) e Scully (2002). Podem-se identificar três grandes eixos na literatura: a) a utilização dos dados dos esportes como laboratório para o teste de teorias econômicas, b) a busca das especifidades econômicas observadas em tais setores, e c) a aplicação das teorias e/ou métodos da economia sobre as atividades esportivas. Abaixo se faz uma panorâmica de cada um desses ramos, ilustrando-os com trabalhos que versam apenas sobre o futebol

A primeira linha de pesquisa vê os gramados como um laboratório para o teste de hipóteses. A ampla disponibilidade de estatísticas esportivas e a transmissão televisiva de jogos têm fornecido os dados para que os testes sejam feitos. Além disso, a maior clareza das regras dos jogos e dos objetivos dos agentes em relação ao mundo econômico em geral torna o esporte atraente para a apreciação de teorias. Um exemplo recente é o paper de Chiappori, Levitt e Groseclose (2002). Nele, os autores examinaram 459 cobranças de pênalti para avaliar se as estratégias do cobrador e do goleiro foram ótimas. Simplificando as opções com que os cobradores e goleiros se deparam (mirar/saltar para a direita, esquerda ou centro), o modelo de teoria dos jogos formulado pelos autores é não-falseado pelas evidências empíricas.

O segundo eixo de pesquisa identifica e teoriza as peculiaridades do esporte que exigem modificações da análise econômica. Uma das principais características apontada por Szymanski (2001) é que nos esportes cada produtor necessita do produto e da qualidade dos outros competidores para fornecer o seu. Um campeonato com um time imbativel levaria à extinção do esporte profissional pela falta de pagantes dispostos a ver um jogo com resultado conhecido de antemão. É esperado, portanto, que haja colusão dos dirigentes esportivos para garantir competições equilibradas. Outra peculiaridade do esporte é que a sua função de produção, tal como a das artes performáticas, restringiria as possibilidades de inovação técnica, levando à doença de custos de Baumol e Bowen (1966). 
A terceira linha busca a aplicação do arsenal teórico e estatístico da Economia sobre o esporte. O objetivo aqui é identificar, entender ou prever aspectos dos esportes com o auxílio da ciência econômica. Por exemplo, a análise de séries temporais, tão freqüente em relação aos agregados macroeconômicos, é aplicada ao número de pagantes em jogos de futebol (GAVIRIA, 2000). Ou, tal como faz Haas (2003), a eficiência técnica dos times de futebol é examinada através da análise de envoltória dos dados (Data Envelopment Analysis). A maior parte dos trabalhos de Sport Economics enquadra-se nesse eixo de pesquisa e, dentro deste, existe uma elevada ocorrência de estudos sobre economia do trabalho. Um bom representante é o paper de Preston e Szymanski (2000) que usa os dados sobre performance e salários para identificar a ocorrência de discriminação racial no mercado inglês de jogadores de futebol.

Ainda nesse eixo, existem trabalhos que utilizam a análise econométrica para buscar os determinantes do desempenho dos times. Estudos como o de Palomino, Rigotti e Rustichini (2000) almejam identificar os fatores microeconômicos (como a habilidade dos times, se o jogo é em casa ou fora, entre outros elementos) que influenciam os resultados das partidas de futebol. Outra vertente busca os fatores macro, não necessariamente ligados ao esporte, que condicionam o desempenho dos times. Hoffman, Ging e Ramasamy (2002) examinaram a posição dos países no ranking da FIFA e mostraram que não apenas fatores econômicos importam, mas também o clima - numa versāo, por assim dizer, esportiva, do paradoxo tropical $^{3}$ - e os fatores culturais. ${ }^{4}$

O presente estudo se enquadra nesta última linha. Nosso objetivo foi o de identificar as determinantes ambientais que condicionam o desempenho dos times. Ou seja, ao invés de buscar os determinantes da performance de um time específico, almejamos identificar quais são as variáveis (não necessária e diretamente ligadas ao jogo) que influenciam o desempenho dos clubes de cada estado brasileiro no Campeonato Brasileiro de Futebol.

\footnotetext{
${ }^{3}$ Os autores encontram o resultado de que temperaturas próximas ao Mediterrâneo são relacionadas positivamente com o desempenho das seleçōes. O paradoxo tropical (ou equatorial) mostra, em estudos cross-country, que países próximos ao Equador possuem as menores rendas per capita do mundo. Explicações para este paradoxo podem ser encontradas, por exemplo, em Sachs (2001),

" Um resultado é o de que a cultura "latina" (englobando países luso-hispânicos) seria mais favorável ao bom desempenho de uma seleção de futebol.
} 


\section{Futebol no Brasil: do rent-seeking ao profit-seeking?}

Embora nosso trabalho se limite à análise do período 1971-1998, é interessante observar-se a evolução do futebol brasileiro. Dadas as limitações de espaço, busca-se, contudo, dar ao leitor um panorama geral desta evolução sob o ponto de vista econômico nas linhas que se seguem.

O futebol começou a ser praticado no Brasil no final do século XIX. ${ }^{5}$ Para Aidar (2002), a prática deste esporte, no Brasil, pode ser divida em quatro momentos: (i) 1923-33, que ele chama de "anos românticos", no qual já se podia notar a emigração de talentos brasileiros para o exterior; (ii) 1933-50, caracterizada pela progressiva popularização do futebol ou, de outra forma, pela sua deselitização; (iii) 1950-70, caracterizada pelo auge do futebol brasileiro (notadamente no front mundial, com o tricampeonato) e, finalmente, (iv) 1970-90, que o autor vê como um período de retrocesso, inclusive em seu acesso (extinção de várzeas com conseqüente diminuição da prática entre os mais pobres). ${ }^{6}$

Apesar de existirem campeonatos regionais no início do século XX, apenas em 1960, com a criação da Copa Libertadores, o campeonato que reúne os times da América Latina, o Brasil viu-se obrigado a criar algum mecanismo de escolha do seu representante naquele torneio. Assim, criou-se a chamada Taça Brasil que duraria até 1968. ${ }^{7}$ Adicionalmente, em 1989 criou-se a Copa do Brasil, descendente da Taça Brasil, e que dá ao campeão uma vaga na Copa Libertadores. ${ }^{8}$ Paralelamente havia outro campeonato, o chamado Torneio Robertão (Rio-São Paulo), que, a partir de 1967, passou a incluir times de outros estados e é considerado o precursor do campeonato brasileiro utilizado neste trabalho.

\footnotetext{
${ }^{5}$ Para um bom resumo sobre o futebol no Brasil, ver Unzelte (2002). Esta seção se baseia fortemente neste texto. Adicionalmente, veja Aidar et alii (2002), notadamente o cap.5.

"Talvez este último "período" deva ser visto com menos pessimismo, pois é também o período no qual se observa uma diversificação dos esportes praticados no Brasil, impulsionados, possivelmente, pelas vitórias mundiais das seleções brasileiras de basquetebol e voleibol. Assim, compensando o efeito de diminuição de vagas, pode haver um outro, derivado da diversificação de esportes praticados, redirecionando talentos para outras modalidades esportivas.

7 Os campeões da Taça Brasil foram: Bahia (1959), Palmeiras (1960, 1967), Cruzeiro (1966), Botafogo (1968) e Santos (1961 a 1965). Ver Placar (2004), p. 128. Curiosamente, times paulistas e cariocas só entravam nas semifinais do campeonato, o que certamente não reduz a acusação de "bairrismo" comum na imprensa especializada de outros estados.

${ }^{8}$ Em 2000 aumentou-se o número de participantes na Libertadores e, em resposta, a CBF decidiu criar mais um campeonato, a Copa dos Campeões. Assim, atualmente, os representantes brasileiros no torneio sul-americano são oriundos do campeonato brasileiro (campeão), da Copa do Brasil (campeão) e da Copa dos Campeões (campeão e vice).
} 
Segundo Aidar (2002), ${ }^{9}$ a prática do futebol foi fortemente influenciada pela atuação estatal, pelo menos em dois períodos importantes: o Estado Novo e o regime implantado em 1964, o que é compatível com o uso político de competições esportivas por regimes políticos autoritários. ${ }^{10}$ Com a redemocratização, entretanto, promulga-se, em 1988, a nova Constituição Federal, na qual a prática de esportes mereceu, segundo o autor, um detalhamento maior do que nas constituições anteriores.

Assim, o final do século XX marcou uma inflexão importante no futebol brasileiro. Primeiramente, na mesma linha de incentivos menos intervencionista - da Constituição, em 1998, promulgou-se a Lei Pelé, que gerou reações diversas no meio, o que motivou alterações em seu texto e nova promulgação em 2000. Uma das alterações que mostra o problema da economia política do futebol foi a mudança no artigo 27 da lei que previa a obrigatoriedade da transformação dos clubes em empresas. A ingerência política de interesses do setor tornou facultativa essa transformação, refletindo um comportamento claramente rent-seeking.

Outro fato marcante - e na mesma direção do que foi dito logo acima - foi a já citada CPI do futebol que gerou edição de uma medida provisória em 2001,11 cujos reflexos vão desde o mercado de trabalho (extinção do passe de jogadores) até a prática contábil dos clubes (obrigatoriedade de apresentação de demonstrativos contábeis). Em 2002, foram criadas a Liga Rio-São Paulo de Futebol S/C Ltda. e Liga Sul-Minas de Futebol Profissional, adotando, cada qual, formatos societários distintos. ${ }^{12}$

Finalmente, é bom lembrar que, durante um período tão longo de tempo como este, o futebol esteve sujeito a mudanças econômicas importantes. Primeiramente, a difusão da transmissão de jogos através da televisão (choque tecnológico), que certamente alterou as estratégias de captação de receitas dos clubes. Em segundo lugar, a participação de investidores estrangeiros no futebol brasileiro (choque institucional), que, embora não seja, atualmente, igual à do final da década dos 1990, é um fator que não se pode ignorar, principal-

\footnotetext{
${ }^{9}$ Especificamente, o cap. 2.

${ }^{10}$ O mais notório exemplo talvez seja o das Olimpíadas de 1936, na Alemanha nazista.

${ }^{11} \mathrm{MP} \mathrm{n}^{\circ} 2.141 / 2001$

12 Uma interessante análise dos diferentes incentivos representados por estes formatos distintos encontra-se no cap. 4 de Aidar (2002). Trata-se de uma análise muito próxima à análise novoinstitucional de arranjos legais, embora não haja referências à literatura econômica no texto.
} 
mente com os incentivos legais para a transformação dos clubes em empresas. ${ }^{13}$

Com todas as imperfeições institucionais, contudo, não é preciso muito para notar que, no Brasil, futebol é assunto de paixão entre torcedores. ${ }^{14}$ Paradoxalmente, contudo, no "país do futebol" não se observam estudos econômicos sobre o mesmo. ${ }^{15} \mathrm{Em}$ áreas do conhecimento nas quais prevalece o senso comum, como se sabe, há grande potencial para pesquisas, e a ausência de trabalhos na linha "esportométrica" parece dever-se à citada ausência de bases de dados primários no Brasil. O presente trabalho pretende contribuir para que tal lacuna comece a fechar-se.

\section{Metodologia econométrica}

Com o objetivo de estimar o desempenho estadual no Campeonato Brasileiro de Futebol da primeira divisão, analisamos a correlação, em termos probabilísticos, de variáveis socioeconômicas e outras da estrutura do futebol com uma variável dependente binária construída para capturar o que definimos como "sucesso", ou o fato de o estado ter o campeão, campeão e vice-campeão, além da presença ou ausência de pelo menos uma equipe de determinado estado entre os três, quatro e cinco primeiros colocados no citado campeonato, no período de 1971 a 1998. Ou seja, trabalhamos com cinco regressandos distintos, tentando explorar a característica de painel dos dados.

Desta forma, visando verificar como tais probabilidades são influenciadas ao longo do tempo, supõe-se a seguinte relação linear:

$\mathrm{Y}^{*}{ }_{\mathrm{it}}=\alpha+\beta \mathrm{X}_{\mathrm{it}}+\varepsilon_{\mathrm{it}}$

onde $Y^{*}=1$ se $Y>0, \alpha$ e $\beta$ são os respectivos parâmetros a serem estimados, $\mathrm{X}_{\mathrm{it}}$ é a matriz dos regressores estado-período, $\varepsilon_{\mathrm{it}}$ é a perturbação aleatória e $\mathrm{Y}_{\mathrm{it}}$ é nossa variável dependente (também estado-período) que, especificamente, pode ser assim caracterizada:

\footnotetext{
13 Năo parece ser muito dificil imaginar que a escassez de dados sobre clubes brasileiros seja derivada da pouca sujeição dos clubes à disciplina do mercado. À medida que capitalistas enxerguem os clubes como potenciais investimentos, os incentivos para uma divulgação mais ampla de dados econômicos dos mesmos deve aumentar, ceteris paribus.

${ }^{14}$ De maneira interessante, Aidar (2002) associa esta característica com a baixa elasticidadepreço da demanda do torcedor típico.

${ }^{15}$ A única exceção, de nosso conhecimento, é Ângelo e Souza (2003), com ênfase em aspectos administrativos do futebol brasileiro. Souza (2004) é um recente exemplo deste tipo de trabalho. Adicionalmente, é interessante examinar a parte II de Aidar et alli (2002).
} 
$\mathrm{Y}=1$, caso pelo menos uma equipe de determinado estado em dado ano tenha terminado o campeonato entre as primeiras equipes (o corte será mais bem definido na próxima seção) e, $\mathrm{Y}=0$, caso contrário.

Pode-se então expressar as probabilidades de sucesso/insucesso através das seguintes expressões:

$\operatorname{Pr}\left(\mathrm{Y}_{\mathrm{it}}=1\right)=F\left(v X_{i t}\right)$

$\operatorname{Pr}\left(\mathrm{Y}_{\mathrm{it}}=0\right)=1-F\left(v X_{\mathrm{i} t}\right)$

De modo que estimaremos em pool:

$\mathrm{Y}_{\mathrm{it}}=F\left(u X_{\mathrm{it}}\right)+\varepsilon_{\mathrm{it}}$

onde $F\left(v X_{\mathrm{i}}\right)$ é a função de distribuição cumulativa de probabilidade. O problema passa a ser encontrar uma relação funcional apropriada para as distribuições de probabilidade acima, que seja capaz de fazer predições consistentes. ${ }^{16}$ Inicialmente estimaremos o modelo logit (por Máxima Verossimilhança - MV - já que se trata de especificação não-linear nos parâmetros), ou seja, pooled logit model. ${ }^{17}$

Como provavelmente existem variáveis omitidas (por exemplo, qualidade dos clubes de cada estado), não observadas e invariantes no tempo correlacionadas (correlação espúria) com algum regressor (por exemplo, PIB), as estimativas de pooled logit model da probabilidade de sucesso seriam inconsistentes.

${ }^{16}$ As formas funcionais mais comuns são as seguintes:

$F\left(v X_{i p}\right)=v X_{i r}$

(linear)

$F\left(v X_{i p}\right)=\frac{e^{v X}}{1+e^{v X_{i}}}$

(logit)

$F\left(u X_{i t}\right)=\frac{1}{\sqrt{2} \pi} \int_{-\infty}^{u X_{i}} e^{-t^{2} / 2}$

(probit)

17 Além disso, aplicamos correção para heterocedasticidade pela matriz de covariância de White. 
Ou seja:

$\varepsilon_{\mathrm{it}}=\eta_{\mathrm{i}}+\mathrm{u}_{\mathrm{it}}, \mathrm{e}$

$\operatorname{Cov}\left(\eta_{\mathrm{i}}, X_{\mathrm{it}}\right) \neq 0$.

Neste sentido, a melhor especificação poderia ser uma que controlasse a heterogeneidade estadual. O método adequado seria o fixed effects logit model, que pode ser estimado via Máxima Verossimilhança Condicional (CML). ${ }^{18}$ Para tanto, uma estatística suficiente para $\eta_{i}$,

$$
S_{i}=\sum_{i=1}^{T_{i}} Y_{i t}
$$

é definida como uma função dos dados tal que a distribuição de $\mathrm{Y}_{\text {it }}$ condicional a $\left(S_{i}, X_{i}, \eta_{i}\right)$ não depende de $\eta_{i}$. Se a estatística existe, os parâmetros podem ser estimados de modo consistente por Máxima Verossimilhança usando a distribuição condicional dos dados. $\mathrm{Na}$ verdade, para saber se fixed effects logit model é superior ao pooled logit model, utilizamos o tradicional teste de Hausman. Vale ressaltar que os estados que não sofrem alterações de $Y_{i t}$ não são usados para estimar os coeficientes, o que explica o número diferente de observações que serão usadas nas regressões apresentadas adiante (HONORE, 2002; GREENE, 2002). Portanto estimamos:

$Y_{i t}=F\left(v X_{i t}+\eta_{i}\right)+u_{i t}$

De modo que:

$\operatorname{Cov}\left(\mathrm{u}_{\mathrm{it}}, \mathrm{X}_{\mathrm{it}}\right)=0$ para quaisquer $(\mathrm{t}, \mathrm{s})$.

Definições das variáveis e suas fontes

A base de dados foi construída como um painel estado-período cobrindo a primeira divisão do Campeonato Brasileiro de Futebol entre 1971 a 1998. As variáveis dependentes binárias (final1, final2,final3, final4 e final5) têm como fonte o CD-ROM Placar (2003) e foram construídas da seguinte forma:

\footnotetext{
${ }^{18}$ Para uma aplicação semelhante do fixed effects logit model, ver, por exemplo, Winkelmann e Winkelmann (1998).
} 
final $1=1$, caso uma equipe de determinado estado em dado ano tenha terminado na primeira colocação do campeonato (sucesso) e,

final $1=0$, caso contrário (insucesso).

final $2=1$, caso pelo menos uma equipe de determinado estado em dado ano tenha terminado como campeão ou vice do campeonato (sucesso) $\mathrm{e}$

final $2=0$, caso contrário (insucesso).

final $3=1$, caso pelo menos uma equipe de determinado estado em dado ano tenha terminado o campeonato entre as três primeiras equipes (sucesso) $\mathrm{e}$,

final $3=0$, caso contrário (insucesso).

final $4=1$, caso pelo menos uma equipe de determinado estado em dado ano tenha terminado o campeonato entre as quatro primeiras equipes (sucesso) e,

final $4=0$, caso contrário (insucesso).

final $5=1$, caso pelo menos uma equipe de determinado estado em dado ano tenha terminado o campeonato entre as cinco primeiras equipes (sucesso) e,

final5 $=0$, caso contrário (insucesso).

As Tabelas 1 a 5 abaixo apresentam um resumo do número de vezes que cada estado obteve "sucesso" no campeonato em todo o período analisado. Como pode ser notado, existe uma concentração muito grande no Sul-Sudeste. Por exemplo, nos 28 anos analisados, as equipes de São Paulo e Rio de Janeiro somam em conjunto $67,85 \%$ dos títulos disputados. Situação semelhante acontece quando definimos sucesso como ter uma equipe entre o campeão e o vice-campeão. Em apenas 7, 5 e 3 anos o estado de São Paulo não teve pelo menos uma equipe entre as três, quatro e cinco melhores (respectivamente, $75 \%, 82,14 \%$ e $89,29 \%$ de aproveitamento nesse sentido) enquanto o mesmo ocorreu 12, 7 e 6 vezes para o estado do Rio de Janeiro (57,14\%, 75\% e 78,57\% de aproveitamento). Minas Gerais e Rio Grande do Sul também se destacam com boas participações. Outros estados apresentam, com algumas exceções (casos de Paraná e Bahia), participações insignificantes em termos de aproveitamento. 
Tabela 1: Distribuição de freqüencia de sucesso/insucesso dos estados no Campeonato Brasileiro - 1971/1998 (sucesso = campeão)

\begin{tabular}{|c|c|c|c|c|c|c|c|}
\hline Estados & Condiçőes & Freq & $\%$ & Estados & Condiçðes & Freq. & $\%$ \\
\hline Alagoas & $\begin{array}{l}\text { insucesso } \\
\text { sucesso }\end{array}$ & $\begin{array}{c}28.00 \\
0.00\end{array}$ & $\begin{array}{c}10000 \\
0.00\end{array}$ & Pernambuco & $\begin{array}{l}\text { insucesso } \\
\text { sucesso }\end{array}$ & $\begin{array}{c}27.00 \\
1.00\end{array}$ & $\begin{array}{c}96.43 \\
3.57\end{array}$ \\
\hline $\begin{array}{l}\text { Amazonas/ Rondônia/ } \\
\text { Acre/ Roraima }\end{array}$ & $\begin{array}{l}\text { insucesso } \\
\text { sucesso }\end{array}$ & $\begin{array}{l}28.00 \\
0.00\end{array}$ & $\begin{array}{l}10000 \\
0.00\end{array}$ & Piauí & $\begin{array}{l}\text { insucesso } \\
\text { sucesso }\end{array}$ & $\begin{array}{c}28.00 \\
0.00\end{array}$ & $\begin{array}{c}100.00 \\
0.00\end{array}$ \\
\hline Bahia & $\begin{array}{l}\text { insucesso } \\
\text { sucesso }\end{array}$ & $\begin{array}{c}27.00 \\
1.00\end{array}$ & $\begin{array}{c}96.43 \\
3.57\end{array}$ & Paraná " & $\begin{array}{l}\text { insucesso } \\
\text { sucesso }\end{array}$ & $\begin{array}{c}27.00 \\
1.00\end{array}$ & $\begin{array}{l}96.43 \\
3.57\end{array}$ \\
\hline Ceará & $\begin{array}{l}\text { insucesso } \\
\text { sucesso }\end{array}$ & $\begin{array}{c}28.00 \\
0.00\end{array}$ & $\begin{array}{c}100.00 \\
0.00\end{array}$ & Rio de Janeiro & $\begin{array}{l}\text { insucesso } \\
\text { sucesso }\end{array}$ & $\begin{array}{l}19.00 \\
9.00\end{array}$ & $\begin{array}{l}67.86 \\
32.14\end{array}$ \\
\hline Espírito Santo & $\begin{array}{l}\text { insucesso } \\
\text { sucesso }\end{array}$ & $\begin{array}{c}28.00 \\
0.00\end{array}$ & $\begin{array}{c}100.00 \\
0.00\end{array}$ & Rio Grande do Norte & $\begin{array}{l}\text { insucesso } \\
\text { sucesso }\end{array}$ & $\begin{array}{c}28.00 \\
0.00\end{array}$ & $\begin{array}{c}100.00 \\
0.00\end{array}$ \\
\hline $\begin{array}{l}\text { Goias/ Tocantins/ } \\
\text { Distrito Federal }\end{array}$ & $\begin{array}{l}\text { insucesso } \\
\text { sucesso }\end{array}$ & $\begin{array}{l}28.00 \\
0.00\end{array}$ & $\begin{array}{c}100.00 \\
0.00\end{array}$ & Paraiba & $\begin{array}{l}\text { insucesso } \\
\text { sucesso }\end{array}$ & $\begin{array}{c}28.00 \\
0.00\end{array}$ & $\begin{array}{c}100.00 \\
0.00\end{array}$ \\
\hline Maranhão & $\begin{array}{l}\text { insucesso } \\
\text { sucesso }\end{array}$ & $\begin{array}{l}28.00 \\
0.00\end{array}$ & $\begin{array}{c}100.00 \\
0.00\end{array}$ & Fio Grande do Sul & $\begin{array}{l}\text { insucesso } \\
\text { sucesso }\end{array}$ & $\begin{array}{c}23.00 \\
5.00\end{array}$ & $\begin{array}{l}82.14 \\
17.86\end{array}$ \\
\hline Minas Gerais & $\begin{array}{l}\text { insucesso } \\
\text { sucesso }\end{array}$ & $\begin{array}{c}27.00 \\
1.00\end{array}$ & $\begin{array}{l}96.43 \\
3.57\end{array}$ & Santa Catarina & $\begin{array}{l}\text { insucesso } \\
\text { sucesso }\end{array}$ & $\begin{array}{c}28.00 \\
0.00\end{array}$ & $\begin{array}{c}100.00 \\
0.00\end{array}$ \\
\hline $\begin{array}{l}\text { Mato Grosso/ } \\
\text { Mato Grosso do Sul }\end{array}$ & $\begin{array}{l}\text { insucesso } \\
\text { sucesso }\end{array}$ & $\begin{array}{c}28.00 \\
0.00\end{array}$ & $\begin{array}{c}100.00 \\
0.00\end{array}$ & Sergipe & $\begin{array}{l}\text { insucesso } \\
\text { sucesso }\end{array}$ & $\begin{array}{c}28.00 \\
0.00\end{array}$ & $\begin{array}{c}100.00 \\
0.00\end{array}$ \\
\hline Pará/ Amapá & $\begin{array}{c}\text { insucesso } \\
\text { sucesso }\end{array}$ & $\begin{array}{c}28.00 \\
0.00\end{array}$ & $\begin{array}{c}100.00 \\
0.00\end{array}$ & Săo Paulo & $\begin{array}{c}\text { insucesso } \\
\text { sucesso }\end{array}$ & $\begin{array}{l}18.00 \\
10.00\end{array}$ & $\begin{array}{l}64.29 \\
35.71\end{array}$ \\
\hline
\end{tabular}

Fonte: elaboração própria a partir de informações do CD-ROM Placar 2003 da editora Abril

Tabela 2: Distribuição de freqüencia de sucesso/insucesso dos estados no Campeonato Brasileiro - 1971/1998 (sucesso = campeão e vice)

\begin{tabular}{|c|c|c|c|c|c|c|c|}
\hline Estados & Condiçơes & Freq & $\%$ & Estados & Condições & Freq. & $\%$ \\
\hline Alagoas & $\begin{array}{l}\text { instcesso } \\
\text { sucesso }\end{array}$ & $\begin{array}{c}28.00 \\
0.00\end{array}$ & $\begin{array}{c}100.00 \\
0.00\end{array}$ & Pernambuco & $\begin{array}{l}\text { insucesso } \\
\text { sucesso }\end{array}$ & $\begin{array}{c}27.00 \\
1.00\end{array}$ & $\begin{array}{c}96.43 \\
357\end{array}$ \\
\hline $\begin{array}{l}\text { Amazonas/ Rondônia/ } \\
\text { Acre/ Roraima }\end{array}$ & $\begin{array}{l}\text { insucesso } \\
\text { sucesso }\end{array}$ & $\begin{array}{c}28.00 \\
0.00\end{array}$ & $\begin{array}{c}100.00 \\
0.00\end{array}$ & Piauí & $\begin{array}{l}\text { insucesso } \\
\text { sucesso }\end{array}$ & $\begin{array}{c}28.00 \\
000\end{array}$ & $\begin{array}{c}100.00 \\
0.00\end{array}$ \\
\hline Bahia & $\begin{array}{l}\text { insucesso } \\
\text { sucesso }\end{array}$ & $\begin{array}{c}26.00 \\
2.00\end{array}$ & $\begin{array}{c}92.86 \\
7.14\end{array}$ & Paraná & $\begin{array}{l}\text { insucesso } \\
\text { sucesso }\end{array}$ & $\begin{array}{c}27.00 \\
1.00\end{array}$ & $\begin{array}{c}96.43 \\
3.57\end{array}$ \\
\hline Ceará & $\begin{array}{l}\text { insucesso } \\
\text { sucesso }\end{array}$ & $\begin{array}{c}2800 \\
0.00\end{array}$ & $\begin{array}{c}10000 \\
0.00\end{array}$ & Rio de Janeiro & $\begin{array}{l}\text { insucesso } \\
\text { sucesso }\end{array}$ & $\begin{array}{l}16.00 \\
12.00\end{array}$ & $\begin{array}{l}57.14 \\
42.86\end{array}$ \\
\hline Espírito Santo & $\begin{array}{l}\text { insucesso } \\
\text { sucesso }\end{array}$ & $\begin{array}{c}28.00 \\
0.00\end{array}$ & $\begin{array}{c}10000 \\
000\end{array}$ & Rio Grande do Norte & $\begin{array}{l}\text { insucesso } \\
\text { sucesso }\end{array}$ & $\begin{array}{c}28.00 \\
0.00\end{array}$ & $\begin{array}{c}100.00 \\
0.00\end{array}$ \\
\hline $\begin{array}{l}\text { Goiás/ Tocantins/ } \\
\text { Distrito Federal }\end{array}$ & $\begin{array}{l}\text { insucesso } \\
\text { sucesso }\end{array}$ & $\begin{array}{c}28.00 \\
0.00\end{array}$ & $\begin{array}{c}100.00 \\
0.00\end{array}$ & Paraiba & $\begin{array}{l}\text { insucesso } \\
\text { sucesso }\end{array}$ & $\begin{array}{c}28.00 \\
0.00\end{array}$ & $\begin{array}{c}100.00 \\
0.00\end{array}$ \\
\hline Marantiáo & $\begin{array}{l}\text { insucesso } \\
\text { sucesso }\end{array}$ & $\begin{array}{c}28.00 \\
0.00\end{array}$ & $\begin{array}{c}100.00 \\
0.00\end{array}$ & Rio Grande do Sul & $\begin{array}{l}\text { insucesso } \\
\text { sucesso }\end{array}$ & $\begin{array}{l}21.00 \\
7.00\end{array}$ & $\begin{array}{l}75.00 \\
25.00\end{array}$ \\
\hline Minas Gerais & $\begin{array}{l}\text { insucesso } \\
\text { sucesso }\end{array}$ & $\begin{array}{c}22.00 \\
600\end{array}$ & $\begin{array}{l}78.57 \\
21.43\end{array}$ & Santa Catarina & $\begin{array}{l}\text { insucesso } \\
\text { sucesso }\end{array}$ & $\begin{array}{l}28.00 \\
0.00\end{array}$ & $\begin{array}{c}100.00 \\
0.00\end{array}$ \\
\hline $\begin{array}{l}\text { Mato Grosso/ } \\
\text { Mato Grosso do Sul }\end{array}$ & $\begin{array}{l}\text { insucesso } \\
\text { sucesso }\end{array}$ & $\begin{array}{c}28.00 \\
0.00\end{array}$ & $\begin{array}{c}100.00 \\
0.00\end{array}$ & Sergipe & $\begin{array}{l}\text { insucesso } \\
\text { sucesso }\end{array}$ & $\begin{array}{c}28.00 \\
0.00\end{array}$ & $\begin{array}{c}100.00 \\
0.00\end{array}$ \\
\hline Pará Amapá & $\begin{array}{l}\text { insucesso } \\
\text { sucesso }\end{array}$ & $\begin{array}{c}28.00 \\
0.00\end{array}$ & $\begin{array}{c}100.00 \\
0.00\end{array}$ & São Paulo & $\begin{array}{l}\text { insucesso } \\
\text { sucesso }\end{array}$ & $\begin{array}{c}9.00 \\
19.00\end{array}$ & $\begin{array}{l}32.14 \\
67.86\end{array}$ \\
\hline
\end{tabular}

Fonte: elaboração própria a partir de informações do CD-ROM Placar 2003 da editora Abril 
Tabela 3: Distribuição de freqüencia de sucesso/insucesso dos estados no Campeonato Brasileiro - 1971/1998 (sucesso = pelo menos uma equipe do estado entre os três primeiros colocados)

\begin{tabular}{|c|c|c|c|c|c|c|c|}
\hline Estados & Condiçōes & Freq & $\%$ & Estados & Condiçð̄es & Freq. & $\%$ \\
\hline Alagoas & $\begin{array}{l}\text { insucesso } \\
\text { sucesso }\end{array}$ & $\begin{array}{c}28.00 \\
0.00\end{array}$ & $\begin{array}{c}100.00 \\
0.00\end{array}$ & Pernambuco & $\begin{array}{l}\text { insucesso } \\
\text { sucesso }\end{array}$ & $\begin{array}{c}28.00 \\
0.00\end{array}$ & $\begin{array}{c}100.00 \\
0.00\end{array}$ \\
\hline $\begin{array}{l}\text { Amazonas/ } \\
\text { Rondónia/ } \\
\text { Acre/ Roraima }\end{array}$ & $\begin{array}{l}\text { insucesso } \\
\text { sucesso }\end{array}$ & $\begin{array}{c}28.00 \\
0.00\end{array}$ & $\begin{array}{c}100.00 \\
0.00\end{array}$ & Piauí & $\begin{array}{l}\text { insucesso } \\
\text { sucesso }\end{array}$ & $\begin{array}{c}28.00 \\
0.00\end{array}$ & $\begin{array}{c}100.00 \\
0.00\end{array}$ \\
\hline Bahia & $\begin{array}{l}\text { insucesso } \\
\text { sucesso }\end{array}$ & $\begin{array}{l}26.00 \\
2.00\end{array}$ & $\begin{array}{l}92.83 \\
7.14\end{array}$ & Paraná & $\begin{array}{l}\text { insucesso } \\
\text { sucesso }\end{array}$ & $\begin{array}{c}27.00 \\
1.00\end{array}$ & $\begin{array}{l}96.43 \\
3.57\end{array}$ \\
\hline Ceará & $\begin{array}{l}\text { insucesso } \\
\text { sucesso }\end{array}$ & $\begin{array}{l}28.00 \\
0.00\end{array}$ & $\begin{array}{c}10000 \\
0.00\end{array}$ & Rio de Janeiro & $\begin{array}{l}\text { insucesso } \\
\text { sucesso }\end{array}$ & $\begin{array}{l}12.00 \\
16.00\end{array}$ & $\begin{array}{l}42.86 \\
57.14\end{array}$ \\
\hline Espírito Santo & $\begin{array}{l}\text { insucesso } \\
\text { sucesso }\end{array}$ & $\begin{array}{c}2800 \\
0.00\end{array}$ & $\begin{array}{c}100.00 \\
0.00\end{array}$ & Rio Grande do Norte & $\begin{array}{l}\text { insucesso } \\
\text { sucesso }\end{array}$ & $\begin{array}{c}2800 \\
0.00\end{array}$ & $\begin{array}{l}100.00 \\
0.00\end{array}$ \\
\hline $\begin{array}{l}\text { Goiás/ Tocantins/ } \\
\text { Distrito Federal }\end{array}$ & $\begin{array}{l}\text { insucesso } \\
\text { sucesso }\end{array}$ & $\begin{array}{l}28.00 \\
0.00\end{array}$ & $\begin{array}{c}100.00 \\
0.00\end{array}$ & Paraiba & $\begin{array}{l}\text { insucesso } \\
\text { sucesso }\end{array}$ & $\begin{array}{c}2800 \\
0.00\end{array}$ & $\begin{array}{l}100.00 \\
0.00\end{array}$ \\
\hline Maranhăo & $\begin{array}{l}\text { insucesso } \\
\text { sucesso }\end{array}$ & $\begin{array}{l}28.00 \\
0.00\end{array}$ & $\begin{array}{c}100.00 \\
0.00\end{array}$ & Rio Grande do Sul & $\begin{array}{l}\text { insucesso } \\
\text { sucesso }\end{array}$ & $\begin{array}{l}1300 \\
1500\end{array}$ & $\begin{array}{l}46.43 \\
53.57\end{array}$ \\
\hline Minas Gerais & $\begin{array}{l}\text { insucesso } \\
\text { sucesso }\end{array}$ & $\begin{array}{l}1300 \\
1500\end{array}$ & $\begin{array}{l}46.43 \\
53.57\end{array}$ & Santa Catarina & $\begin{array}{l}\text { insucesso } \\
\text { sucesso }\end{array}$ & $\begin{array}{c}28.00 \\
0.00\end{array}$ & $\begin{array}{c}100.00 \\
0.00\end{array}$ \\
\hline $\begin{array}{l}\text { Mato Grosso/ } \\
\text { Mato Grosso do Sul }\end{array}$ & $\begin{array}{l}\text { insucesso } \\
\text { sucesso }\end{array}$ & $\begin{array}{c}27.00 \\
1.00\end{array}$ & $\begin{array}{l}96.43 \\
3.57\end{array}$ & Sergipe & $\begin{array}{l}\text { insucesso } \\
\text { sucesso }\end{array}$ & $\begin{array}{c}28.00 \\
0.00\end{array}$ & $\begin{array}{c}100.00 \\
0.00\end{array}$ \\
\hline Pará Amapá & $\begin{array}{c}\text { insucesso } \\
\text { sucesso }\end{array}$ & $\begin{array}{c}28.00 \\
0.00\end{array}$ & $\begin{array}{c}100.00 \\
000\end{array}$ & São Paulo & $\begin{array}{c}\text { insucesso } \\
\text { sucesso }\end{array}$ & $\begin{array}{l}7.00 \\
21.00\end{array}$ & $\begin{array}{l}25.00 \\
75.00\end{array}$ \\
\hline
\end{tabular}

Fonte: elaboração própria a partir de informaçōes do CD-ROM Placar 2003 da editora Abril

Tabela 4: Distribuição de freqüencia de sucesso/insucesso dos estados no Campeonato Brasileiro - 1971/1998 (sucesso = pelo menos uma equipe do estado entre os quatro primeiros colocados)

\begin{tabular}{|c|c|c|c|c|c|c|c|}
\hline Estados & Condiçбes & Freq & $\%$ & Estados & Condiç̧es & Freq. & $\%$ \\
\hline Alagoas & $\begin{array}{c}\text { insucesso } \\
\text { sucesso }\end{array}$ & $\begin{array}{c}28.00 \\
0.00\end{array}$ & $\begin{array}{c}100.00 \\
0.00\end{array}$ & Pernambuco & $\begin{array}{l}\text { insucesso } \\
\text { sucesso }\end{array}$ & $\begin{array}{l}27.00 \\
1.00\end{array}$ & $\begin{array}{c}9643 \\
3.57\end{array}$ \\
\hline $\begin{array}{l}\text { Amazonas/ } \\
\text { Rondónia/ } \\
\text { Acre/ Roraima }\end{array}$ & $\begin{array}{l}\text { insucesso } \\
\text { sucesso }\end{array}$ & $\begin{array}{l}28.00 \\
0.00\end{array}$ & $\begin{array}{c}100.00 \\
0.00\end{array}$ & Piauí & $\begin{array}{l}\text { insucesso } \\
\text { sucesso }\end{array}$ & $\begin{array}{c}2800 \\
0.00\end{array}$ & $\begin{array}{c}100.00 \\
0.00\end{array}$ \\
\hline Bahia : & $\begin{array}{l}\text { insucesso } \\
\text { sucesso }\end{array}$ & $\begin{array}{c}25.00 \\
3.00\end{array}$ & $\begin{array}{l}8929 \\
1071\end{array}$ & Paraná & $\begin{array}{l}\text { insucesso } \\
\text { sucesso }\end{array}$ & $\begin{array}{c}23.00 \\
500\end{array}$ & $\begin{array}{l}82.14 \\
17.86\end{array}$ \\
\hline Ceará & $\begin{array}{l}\text { insucesso } \\
\text { sucesso }\end{array}$ & $\begin{array}{c}28.00 \\
0.00\end{array}$ & $\begin{array}{c}10000 \\
0.00\end{array}$ & Rio de Janeiro & $\begin{array}{l}\text { insucesso } \\
\text { sucesso }\end{array}$ & $\begin{array}{l}700 \\
21.00\end{array}$ & $\begin{array}{l}2500 \\
7500\end{array}$ \\
\hline Espírito Santo & $\begin{array}{l}\text { insucesso } \\
\text { sucesșo }\end{array}$ & $\begin{array}{c}28.00 \\
0.00\end{array}$ & $\begin{array}{c}10000 \\
0.00\end{array}$ & Rio Grande do Norte & $\begin{array}{l}\text { insucesso } \\
\text { sucesso }\end{array}$ & $\begin{array}{c}28.00 \\
0.00\end{array}$ & $\begin{array}{c}10000 \\
0.00\end{array}$ \\
\hline $\begin{array}{l}\text { Goiás/ Tocantins; } \\
\text { Distrito Federal }\end{array}$ & $\begin{array}{l}\text { insucesso } \\
\text { sucesso }\end{array}$ & $\begin{array}{c}27.00 \\
1.00\end{array}$ & $\begin{array}{l}96.43 \\
3.57\end{array}$ & Paraiba & $\begin{array}{l}\text { insucesso } \\
\text { sucesso }\end{array}$ & $\begin{array}{c}28.00 \\
0.00\end{array}$ & $\begin{array}{c}100.00 \\
0.00\end{array}$ \\
\hline Maranhão & $\begin{array}{l}\text { insucesso } \\
\text { sucesso }\end{array}$ & $\begin{array}{l}28.00 \\
0.00\end{array}$ & $\begin{array}{c}100.00 \\
0.00\end{array}$ & Rio Grande do Sul & $\begin{array}{l}\text { insucesso } \\
\text { sucesso }\end{array}$ & $\begin{array}{l}11.00 \\
17.00\end{array}$ & $\begin{array}{l}39.29 \\
60.71\end{array}$ \\
\hline Minas Gerais & $\begin{array}{l}\text { insucesso } \\
\text { sucesso }\end{array}$ & $\begin{array}{l}10.00 \\
18.00\end{array}$ & $\begin{array}{l}35.71 \\
64.29\end{array}$ & Santa Catarina & $\begin{array}{l}\text { insucesso } \\
\text { sucesso }\end{array}$ & $\begin{array}{c}28.00 \\
0.00\end{array}$ & $\begin{array}{c}100.00 \\
0.00\end{array}$ \\
\hline $\begin{array}{l}\text { Mato Grosso/ } \\
\text { Mato Grosso do Sul }\end{array}$ & $\begin{array}{l}\text { insucesso } \\
\text { sucesso }\end{array}$ & $\begin{array}{c}27.00 \\
1.00\end{array}$ & $\begin{array}{c}96.43 \\
3.57\end{array}$ & Sergipe & $\begin{array}{l}\text { insucesso } \\
\text { sucesso }\end{array}$ & $\begin{array}{l}28.00 \\
0.00\end{array}$ & $\begin{array}{c}100.00 \\
0.00\end{array}$ \\
\hline Pará/ Amapá & $\begin{array}{l}\text { insucesso } \\
\text { sucesso }\end{array}$ & $\begin{array}{c}28.00 \\
0.00\end{array}$ & $\begin{array}{c}100.00 \\
0.00\end{array}$ & São Paulo & $\begin{array}{l}\text { insucesso } \\
\text { sucesso }\end{array}$ & $\begin{array}{c}5.00 \\
23.00\end{array}$ & $\begin{array}{l}17.86 \\
82.14\end{array}$ \\
\hline
\end{tabular}

Fonte: elaboração própria a partir de informações do CD-ROM Placar 2003 da editora Abril 
Tabela 5: Distribuição de freqüencia de sucesso/insucesso dos estados no Campeonato Brasileiro - 1971/1998 (sucesso = pelo menos uma equipe do estado entre os cinco primeiros colocados)

\begin{tabular}{|c|c|c|c|c|c|c|c|}
\hline Estados & Condiçðes & Freq & $\%$ & Estados & Condiçöes & Freq & $\%$ \\
\hline Alagoas & $\begin{array}{l}\text { insucesso } \\
\text { sucesso }\end{array}$ & $\begin{array}{l}28.00 \\
0.00\end{array}$ & $\begin{array}{c}100.00 \\
0.00\end{array}$ & Pernambuco & $\begin{array}{l}\text { insucesso } \\
\text { sucesso }\end{array}$ & $\begin{array}{c}25.00 \\
3.00\end{array}$ & $\begin{array}{l}89.29 \\
10.71\end{array}$ \\
\hline $\begin{array}{l}\text { Amazonas/ } \\
\text { Rondônia/ } \\
\text { Acre/ Roraima }\end{array}$ & $\begin{array}{l}\text { insucesso } \\
\text { sucesso }\end{array}$ & $\begin{array}{l}2800 \\
0.00\end{array}$ & $\begin{array}{c}100.00 \\
0.00\end{array}$ & Piauí & $\begin{array}{l}\text { insucesso } \\
\text { sucesso }\end{array}$ & $\begin{array}{c}2800 \\
0.00\end{array}$ & $\begin{array}{c}10000 \\
0.00\end{array}$ \\
\hline Bahia & $\begin{array}{l}\text { insucesso } \\
\text { sucesso }\end{array}$ & $\begin{array}{l}2300 \\
500\end{array}$ & $\begin{array}{l}82.14 \\
1786\end{array}$ & Paraná & $\begin{array}{l}\text { insucesso } \\
\text { sucesso }\end{array}$ & $\begin{array}{c}22.00 \\
6.00\end{array}$ & $\begin{array}{l}78.57 \\
21.43\end{array}$ \\
\hline Ceará & $\begin{array}{l}\text { insucesso } \\
\text { sucesso }\end{array}$ & $\begin{array}{c}28.00 \\
0.00\end{array}$ & $\begin{array}{c}100.00 \\
0.00\end{array}$ & Rio de Janeiro & $\begin{array}{l}\text { insucesso } \\
\text { sucesso }\end{array}$ & $\begin{array}{c}600 \\
2200\end{array}$ & $\begin{array}{l}21.43 \\
78.57\end{array}$ \\
\hline Espirito Santo & $\begin{array}{l}\text { insucesso } \\
\text { sucesso }\end{array}$ & $\begin{array}{l}28.00 \\
0.00\end{array}$ & $\begin{array}{c}100.00 \\
0.00\end{array}$ & Rio Grande do Norte & $\begin{array}{l}\text { insucesso } \\
\text { sucesso }\end{array}$ & $\begin{array}{l}28.00 \\
0.00\end{array}$ & $\begin{array}{c}100.00 \\
000\end{array}$ \\
\hline $\begin{array}{l}\text { Goiás/ Tocantins/ } \\
\text { Distrito Federal }\end{array}$ & $\begin{array}{l}\text { insucesso } \\
\text { sucesso }\end{array}$ & $\begin{array}{c}27.00 \\
1.00\end{array}$ & $\begin{array}{l}96.43 \\
3.57\end{array}$ & Paraiba & $\begin{array}{l}\text { insucesso } \\
\text { sucesso }\end{array}$ & $\begin{array}{c}28.00 \\
0.00\end{array}$ & $\begin{array}{l}100.00 \\
0.00\end{array}$ \\
\hline Maranhăo & $\begin{array}{l}\text { insucesso } \\
\text { sucesso }\end{array}$ & $\begin{array}{c}28.00 \\
0.00\end{array}$ & $\begin{array}{c}100.00 \\
0.00\end{array}$ & Rio Grande do Sul & $\begin{array}{l}\text { insucesso } \\
\text { sucesso }\end{array}$ & $\begin{array}{l}10.00 \\
18.00\end{array}$ & $\begin{array}{l}35.71 \\
64.29\end{array}$ \\
\hline Minas Gerais & $\begin{array}{l}\text { insucesso } \\
\text { sucesso }\end{array}$ & $\begin{array}{c}9.00 \\
19.00\end{array}$ & $\begin{array}{l}32.14 \\
6786\end{array}$ & Santa Catarina & $\begin{array}{l}\text { insucesso } \\
\text { sucesso }\end{array}$ & $\begin{array}{l}28.00 \\
0.00\end{array}$ & $\begin{array}{c}100.00 \\
0.00\end{array}$ \\
\hline $\begin{array}{l}\text { Mato Grosso' } \\
\text { Mato Grosso do Sul }\end{array}$ & $\begin{array}{l}\text { insucesso } \\
\text { sucesso }\end{array}$ & $\begin{array}{c}27.00 \\
1.00\end{array}$ & $\begin{array}{l}96.43 \\
3.57\end{array}$ & Sergipe & $\begin{array}{l}\text { insucesso } \\
\text { sucesso }\end{array}$ & $\begin{array}{c}28.00 \\
0.00\end{array}$ & $\begin{array}{c}100.00 \\
0.00\end{array}$ \\
\hline Paráa Amapá & $\begin{array}{c}\text { insucesso } \\
\text { sucesso }\end{array}$ & $\begin{array}{c}28.00 \\
0.00\end{array}$ & $\begin{array}{c}100.00 \\
0.00\end{array}$ & São Paulo & $\begin{array}{c}\text { insucesso } \\
\text { sucesso }\end{array}$ & $\begin{array}{r}3.00 \\
25.00\end{array}$ & $\begin{array}{l}10.71 \\
89.29\end{array}$ \\
\hline
\end{tabular}

Fonte: elaboração própria a partir de informações do CD-ROM Placar 2003 da editora Abril

A primeira variável explicativa da probabilidade de "sucesso" utilizada é a renda média, medida pelos PIBs reais per capita dos estados brasileiros (pibpc), calculados com base em informações de Azzoni (1997). ${ }^{19}$ Neste caso, tentamos verificar se regiões mais ricas (com maior acesso a equipamentos e tempo disponível para os esportes) apresentam probabilidade diferenciada na obtenção do "sucesso" futebolístico. Esperamos que a relação entre a probabilidade de "sucesso" e renda média seja positiva. ${ }^{20} \mathrm{~A}$ variável renda média ao quadrado (pibpc2) também foi incluída com o objetivo de captu-

${ }^{19}$ De 1971 a 1980, a população foi calculada a partir de interpolação geométrica nos anos censitários. Detalhes dos cálculos podem ser obtidos com os autores.

${ }^{20}$ Szymanski (2001) mostra que existe uma outra relaçāo entre renda e futebol, através da atratividade das competições. Introduzindo o conceito de balanço competitivo, o autor postula que um aumento da desigualdade de renda intertimes reduz o balanço competitivo, gerando uma redução do interesse dos torcedores, já que fica mais fácil prever o resultado final do campeonato (o time mais rico terá alta chance de ser o vencedor). Esta relação não será testada aqui, mas é um tópico importante numa análise mais detalhada de campeonatos de futebol, na qual se inclua algum controle para o efeito dos fãs sobre o desempenho dos times. 
rar reduções que podem ocorrer na probabilidade para regiōes com altíssima renda dada a possível substituição no "consumo" do futebol (Hoffman et al., 2002). ${ }^{21}$

Outra variável independente incluída nas regressões, "timeabs", inspirada em Olson (1982), busca representar o trade-off entre eficiência (derivada do tempo de prática de futebol no estado de forma organizada, através de clubes) e redistribuição (oriunda do surgimento de atividades de "cartolas" no estado). Note que o efeito desta variável é ambíguo. Por exemplo, imagine que a eficiência de um estado na geração de esportes se sobreponha à ação dos cartolas estaduais. Dessa forma, este estado apresentará mais times nas primeiras colocações de um campeonato e o sinal esperado seria positivo. Por outro lado, se em um estado as ações dos cartolas prevalecem, os times terão seu desempenho prejudicado e o sinal esperado desta variável será negativo (podemos chamar este de efeito político de longo prazo). A fonte desta e das próximas variáveis é o CD-ROM Placar (2003).

A inclusão de uma variável que capture o percentual relativo de clubes (equip) é importante já que a probabilidade de "sucesso" estadual deve ser função crescente do número de clubes que defendem cada estado. Além disso, como o Campeonato Brasileiro de Futebol é conhecido pelas mudanças constantes de regulamentações (número de equipes, "viradas de mesa" etc.), tal variável pode acabar capturando o efeito da força política sobre a Confederação Brasileira de Futebol (CBF) de estados que supostamente a possuem, no caso, São Paulo e Rio de Janeiro. Portanto, efeito positivo é esperado (esta corresponderia a um efeito político de curto prazo). A Tabela 6 abaixo é evidência inicial a este respeito. Enquanto São Paulo e Rio de Janeiro apresentam representação média de, respectivamente, 23 e $16 \%$, para a maioria dos outros tal medida não passa de $6 \%$.

Finalmente, tentamos estimar a influência do artilheiro (art) sobre a probabilidade de "sucesso". Neste caso, efeito ambíguo é pos-

\footnotetext{
${ }^{21}$ Uma possivel explicação repousa na relação entre extensão do mercado e divisão do trabalho apontada por Adam Smith. Desta forma, economias relativamente pequenas não possuem trocas econômicas suficientes para gerar uma ampla diversidade de esportes, especializandose em alguns poucos. Espera-se, por outro lado, que isto beneficie o desempenho desta economia em torneios esportivos especializados, mas não em eventos multiesportivos como as Olimpíadas.
} 
sível, pelo menos teoricamente, já que, além do efeito positivo óbvio, poderíamos esperar que, em algumas equipes medíocres (ou mesmo medianas), o atacante pudesse se destacar em comparação ao restante do grupo (exemplo do Goiás no ano de 1989 que teve artilheiro, mas não terminou entre os quatro primeiros).

Tabela 6: Percentual relativo médio de equipes por estado no Campeonato Brasileiro - 1971/1998

\begin{tabular}{l|c|l|l|c}
\hline Estados & $\%$ & & Estados & $\%$ \\
\hline Alagoas & 1.39 & Pernambuco & 6.48 \\
Amazonas/ Rondônia/ Acre/ Roraima & 1.72 & Piaui & 1.16 \\
Bahia & 5.95 & Paraná & 6.24 \\
Ceará & 2.26 & Rio de Janeiro & 16.17 \\
Espírito Santo & 1.33 & Rio Grande do Norte & 1.74 \\
Goiás/ Tocantins/ Distrito Federal & 4.60 & Paraiba & 1.13 \\
Maranhão & 1.19 & Rio Grande do Sul & 8.01 \\
Minas Gerais & 8.73 & Santa Catarina & 2.36 \\
Mato Grosso/ Mato Grosso do Sul & 2.26 & Sergipe & 1.39 \\
Pará/ Amapá & 2.80 & São Paulo & 23.08 \\
\hline
\end{tabular}

Fonte: elaboração própria a partir de informaçóes do CD-ROM Placar 2003 da editora Abril

Resumindo, apresentamos as estimativas das regressões com as metodologias discutidas anteriormente na seguinte equação:

final $=F($ pibpc, pibpc2, timeabs, equip, art $)+\varepsilon$

sendo que se espera, portanto:

$\frac{\partial f \text { final }}{\partial p i b p c}>0 ; \quad \frac{\partial \text { final }}{\partial p i b p c^{2}}<0 ; \quad \frac{\partial f \text { inal }}{\partial \text { timeabs }}>0$ ou $<0 ; \frac{\partial f \text { inal }}{\partial e q u i p}>0 ;$

$\frac{\text { dfinal }}{\text { dart }}>0$ ou $<0$ 


\section{Resultados 22}

Os resultados das estimativas econométricas das cinco variáveis dependentes são reproduzidos nas tabelas 7 e 8 . Para o pool logit foram usadas 560 observações, 20 estados $^{23}$ e 28 anos (painel balanceado). Como dito anteriormente, os estados que não sofrem alterações de $Y_{\text {it }}$ não são usados para estimar os coeficientes via fixed effects logit (o que explica o número diferente de observações usadas).

Tabela 7: Regressōes pool logit com correções para heterocedasticidade (ML White) - (estatísticas-z são apresentadas abaixo dos coeficientes estimados)

\begin{tabular}{|c|c|c|c|c|c|c|c|c|c|c|}
\hline Variável dependente & final 1 & & final 2 & & final 3 & & final 4 & & final 5 & \\
\hline pibpc & $\begin{array}{c}0.9812 \\
200\end{array}$ & ** & $\begin{array}{c}0.6764 \\
2.11\end{array}$ & ** & $\begin{array}{c}14176 \\
4.06\end{array}$ & * & $\begin{array}{c}1.7525 \\
4.42\end{array}$ & * & $\begin{array}{c}1.3795 \\
4.03\end{array}$ & * \\
\hline pibpc (quadrado) & $\begin{array}{c}-0.0506 \\
-1.55\end{array}$ & & $\begin{array}{c}-0.0308 \\
-1.34\end{array}$ & & $\begin{array}{c}-0.0818 \\
-3.13\end{array}$ & & $\begin{array}{c}-0.1100 \\
-3.65\end{array}$ & & $\begin{array}{c}-0.0864 \\
-3.22\end{array}$ & \\
\hline timeabs & $\begin{array}{c}0.0003 \\
001\end{array}$ & & $\begin{array}{c}-0.0125 \\
-0.60\end{array}$ & & $\begin{array}{c}-0.0226 \\
-1.48\end{array}$ & & $\begin{array}{c}-0.2069 \\
-1.47\end{array}$ & & $\begin{array}{c}-0.0153 \\
-1.20\end{array}$ & \\
\hline equip & $\begin{array}{c}0.089 \\
2.16\end{array}$ & ** & $\begin{array}{c}0.1541 \\
.374\end{array}$ & * & $\begin{array}{c}0.2020 \\
4.30\end{array}$ & * & $\begin{array}{c}0.2677 \\
6.08\end{array}$ & * & $\begin{array}{c}0.2725 \\
5.92\end{array}$ & * \\
\hline art & $\begin{array}{c}2.6929 \\
4.93\end{array}$ & * & $\begin{array}{c}2.1666 \\
398\end{array}$ & * & $\begin{array}{c}1.3752 \\
2.43\end{array}$ & ** & $\begin{array}{c}1.4321 \\
2.36\end{array}$ & ** & $\begin{array}{c}1.3774 \\
2.31\end{array}$ & ** \\
\hline constante & $\begin{array}{c}-8.3249 \\
-3.41\end{array}$ & * & $\begin{array}{c}-5.9234 \\
-4.13\end{array}$ & * & $\begin{array}{l}-6.9805 \\
-4.75\end{array}$ & & $\begin{array}{c}-7.9353 \\
-5.10\end{array}$ & * & $\begin{array}{c}-6.8205 \\
-5.29\end{array}$ & * \\
\hline$N^{0}$ de observações & 560 & & 560 & & 560 & & 560 & & 560 & \\
\hline Log-likelihood & -61.1148 & & .86 .8452 & & -1169179 & & -126.9508 & & -140.6886 & \\
\hline
\end{tabular}

Fonte: Elaboração dos autores a partir dos resultados das regressões.

Com relação às regressões pool logit, podemos notar na Tabela 7 que o parâmetro estimado da variável renda média, medida pelo PIB per capita (pibpc), apresenta-se sempre com sinal correto positivo e significativo com pelo menos $95 \%$ de confiança. Ou seja, regiões de maior renda apresentam maior chance de ter pelo menos uma equi-

${ }^{22}$ Estatísticas descritivas e correlações bivariadas das variáveis utilizadas encontram-se no Anexo Estatístico A.

${ }^{23}$ Alguns estados foram agrupados como um único. Ver, por exemplo, Tabela 1. 
pe entre as melhores do campeonato brasileiro. ${ }^{24} \mathrm{O}$ coeficiente da renda média ao quadrado (pibpc2) apresenta sinal negativo (também conforme esperado), mas sua significância estatística é aceitável apenas em três das cinco regressões (quando se exige menos na consideração do que é "sucesso").

A variável "experiência" em competições (timeabs) não apresenta significância estatística. Qualitativamente talvez o efeito negativo resulte da argumentação original de esclerose institucional proposta por Olson (1982). Isto é, a história de um estado no esporte teria sido anulada pelo efeito "cartolagem".

Como era esperado, maior representatividade nas competições (equip) traz impacto positivo e significativo ao "sucesso" futebolístico estadual. Finalmente, a presença do artilheiro (art) gera impacto positivo, ao nível de significância de $5 \%$, sobre a probabilidade de "sucesso" nas competições. Ou seja, os times bem-sucedidos tiveram seus gols concentrados em alguns jogadores. Isso sugere a incapacidade das defesas de anular a habilidade individual dos goleadores, o que é corroborado pelo fato de o mercado premiar os jogadores de ataque com salários mais altos do que os defensores. ${ }^{25}$

O principal problema dos resultados anteriores é que, na presença de características individuais não observáveis, os estimadores obtidos serão viesados e inconsistentes. É importante, portanto, refazer as estimativas utilizando estimadores que exploram a característica de painel dos dados para modelos com variável dependente discreta (via Máxima Verossimilhança Condicional) e comparar com aqueles do pool. Além disso, como em vários anos muitos estados não tiveram representantes no campeonato brasileiro, trabalhamos apenas com aqueles que sofrem alterações de $\mathrm{Y}_{\mathrm{it}}$. A Tabela 8 resume os resultados encontrados para esta nova estimação.

\footnotetext{
24 Note-se que, se vale o efeito do balanço competitivo anteriormente citado, então essa desigualdade pode ser um indicador de que políticas redutoras de desigualdade econômica têm efeitos não apenas no nível de renda das sociedades estaduais, mas também sobre o futebol local, tornando a competição mais equilibrada.

${ }^{25}$ Vale a pena qualificar que os regressores apresentam-se significativos estatisticamente em conjunto no caso dos cinco modelos.
} 
Tabela 8: Regressōes fixed effects logit (CML)

(estatísticas-z são apresentadas abaixo dos coeficientes estimados)

\begin{tabular}{|c|c|c|c|c|c|c|c|c|c|}
\hline Variável dependente & final 1 & final 2 & & final 3 & & final 4 & & final 5 & \\
\hline pibpc & $\begin{array}{c}0.5833 \\
0.59\end{array}$ & $\begin{array}{c}0.3705 \\
0.50\end{array}$ & & $\begin{array}{c}1.1387 \\
1.62\end{array}$ & $* * *$ & $\begin{array}{c}2.0091 \\
2.78\end{array}$ & * & $\begin{array}{c}2.1133 \\
2.95\end{array}$ & * \\
\hline pibpc (quadrado) & $\begin{array}{c}-0.0270 \\
-0.51\end{array}$ & $\begin{array}{c}-0.0198 \\
-0.46\end{array}$ & & $\begin{array}{l}-0.0597 \\
-0.138\end{array}$ & & $\begin{array}{c}-0.1325 \\
-2.75\end{array}$ & * & $\begin{array}{c}-0.1506 \\
-2.95\end{array}$ & * \\
\hline timeabs & $\begin{array}{c}0.0463 \\
-0.89\end{array}$ & $\begin{array}{l}-0.371 \\
-0.84\end{array}$ & & $\begin{array}{c}-0.0793 \\
-1.90\end{array}$ & $\star \star \star \star$ & $\begin{array}{c}-0.0784 \\
-1.87\end{array}$ & $* * *$ & $\begin{array}{c}-0.0885 \\
-2.14\end{array}$ & $* *$ \\
\hline equip & $\begin{array}{c}0.7269 \\
1.19\end{array}$ & $\begin{array}{c}0.0875 \\
1.60\end{array}$ & $\star \star \star$ & $\begin{array}{c}0.1195 \\
2.14\end{array}$ & $\star \star$ & $\begin{array}{c}0.1091 \\
1.88\end{array}$ & $* * *$ & $\begin{array}{c}0.0712 \\
1.19\end{array}$ & \\
\hline art & $\begin{array}{c}2.3473 \\
4.52\end{array}$ & $\begin{array}{c}1.6517 \\
6.43\end{array}$ & * & $\begin{array}{c}08822 \\
1.75\end{array}$ & $* * *$ & $\begin{array}{c}1.0270 \\
1.80\end{array}$ & $* * *$ & $\begin{array}{c}1.0424 \\
1.73\end{array}$ & $\star * \star \star$ \\
\hline $\mathrm{N}^{\circ}$ de observações & 196 & 196 & & 196 & & 196 & & 196 & \\
\hline Log-likelihood & -45.4393 & -64.3785 & & -73.2664 & & 80.1937 & & 82.5616 & \\
\hline
\end{tabular}

Fonte: Elaboração dos autores a partir dos resultados das regressões.

Uma inspeção na relação entre a renda média (pibpc) e a probabilidade de "sucesso" revela-nos que o efeito estimado é, como esperado, positivo (significativo a $10 \%$ em três dos cinco modelos, novamente quando se exige menos na consideração do que é "sucesso"). As estimativas geram resultado sempre como esperado para a variável PIB per capita ao quadrado (pibpc2) apenas para os dois últimos modelos. Ou seja, nestes dois casos, podemos considerar que o futebol é um esporte muito pouco intensivo em capital, o que proporciona competição com outras modalidades mais capital-intensivas em estados mais ricos.

Ambas as dummies de representação (equip) e de artilharia (art) apresentam coeficientes com sinais positivos ${ }^{26}$ e significativos na maioria dos modelos. Portanto, atuam aumentando a probabilidade de "sucesso" futebolístico estadual. Em cálculos não reportados aqui, com a utilização de uma dummy unitária para São Paulo e Rio de Janeiro como proxy de força política, obtemos sinal esperado positivo e significativo. A força e a significância desta dummy reduzemse muito quando acrescentamos à regressão a variável de representatividade de clubes. Neste sentido, além da evidência das freqüências apresentadas na Tabela 6 , fica claro que a variável de representatividade estadual na competição acaba por capturar tam-

\footnotetext{
${ }^{26}$ Observe que para "artilharia" não se esperava um sinal positivo ou negativo. Entretanto, para "equip", o sinal positivo está de acordo com o que se esperava.
} 
bém o fato que o regulamento da competição muda com muita freqüência de forma a favorecer alguns dos entes federativos, ou seja, captura o efeito de curto prazo da força política. ${ }^{27}$ A variável que captaria "experiência" (timeabs) apresenta sinal negativo, o que nos sugere esclerose institucional de Olson (1982).

Novamente as razões de verossimilhança são altas, o que indica que os regressores são significativos estatisticamente em conjunto. Os resultados dos fixed effects logit models, quando "sucesso" é definido como ser campeão e campeão/vice, não são tão bons quando comparados com os do pool logit. Além disso, o teste de Hausman rejeita o modelo com efeitos fixos para o caso em que a variável dependente é ser campeão, o que não ocorre com os modelos para as outras variáveis dependentes (ver Anexo Estatístico B).

Em relação ao PIB per capita (e PIB per capita ao quadrado) vale um comentário. Com as equações em mãos, pode-se calcular o ponto ótimo de renda, ou seja, o nível de renda que traria a maior probabilidade possivel de se ter pelo menos uma equipe entre as melhores do campeonato. Uma aproximação para esse valor poderia ser observada plotando a probabilidade prevista pelo modelo contra o PIB per capita. A Figura 1 abaixo apresenta, como exemplo, o PIB per capita que maximiza a probabilidade de sucesso (estimada via CML)

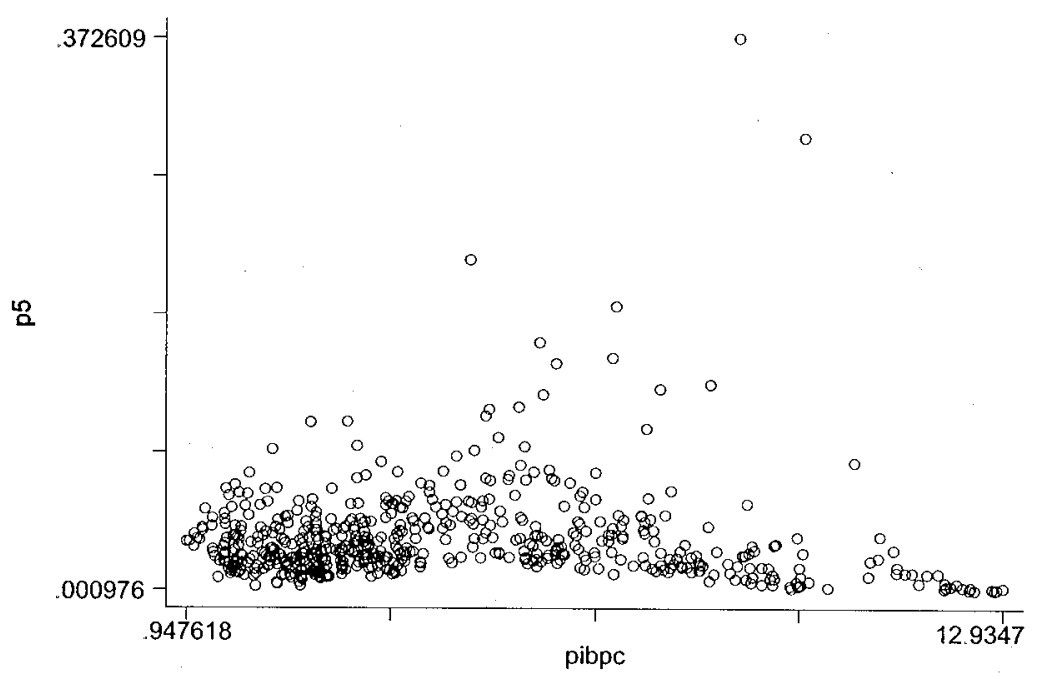

Figura 1: PIB per capita que Maximiza a Probalidade de Sucesso (5 primeiros). Fonte: Elaboração dos autores a partir dos resultados das regressões.

${ }^{27}$ Além disso, a dummy citada poderia estar captando outros efeitos que não a força política. Agradecemos a Gilson Geraldino Jr. (IBMEC-MG) por esta observação. 
quando esta é definida como ter, em dado ano, pelo menos uma equipe entre os cinco melhores colocados no Campeonato Brasileiro de Futebol. Podemos notar que o valor do PIB per capita é aproximadamente $\mathrm{R} \$ 10$ mil anuais. ${ }^{28}$ Portanto, a partir deste valor, aumentos do PIB deslocariam parte do interesse de determinada região para modalidades esportivas mais capital-intensivas.

\section{Conclusões}

Os brasileiros vêem seu próprio país como o país do futebol. Entretanto, pouco tem sido feito no sentido de se entenderem as motivações econômicas desse popular esporte nacional. Há uma grande assimetria entre o que se publica na mídia sobre este esporte e o que se entende, cientificamente, do assunto. Como se sabe, o senso comum nem sempre é validado pela ciência.

Neste artigo, buscamos entender, economicamente, certos determinantes do desempenho de times de futebol no Brasil. A análise aqui apresentada, a nosso ver, pioneira, enfrenta diversos problemas cuja superação posterior não está descartada. Boa parte das limitações de nossos dados encontra-se no curto intervalo de tempo no qual foram mensuradas as contas regionais, bem como a escassez de indicadores sociais com periodicidades anuais que bem poderiam controlar nossas estimações para fatores como a infra-estrutura social estadual utilizada para geração de excelência esportiva, além de informações referentes aos clubes de futebol.

Resumidamente, as estimativas mostram que um aumento no PIB real per capita geraria um aumento na probabilidade de "sucesso". Além disso, níveis de PIB per capita muito altos deslocariam parte do interesse de determinada região para modalidades esportivas mais capital-intensivas. Portanto, a relação entre as probabilidades de sucesso e a renda média apresenta-se em formato de " $U$ invertido". A força política (representação) aumenta a probabilidade de "sucesso" assim como o artilheiro. A variável que capta efeito político de longo prazo reduz a chance de o estado colocar uma equipe entre as melhores do campeonato brasileiro de futebol.

Os resultados encontrados mostram que, pelo menos para o caso brasileiro, existem fatos estilizados (ou determinantes econômicos) no futebol e, portanto, a Economia pode contribuir para entender melhor seu funcionamento.

${ }^{28}$ Hoffmann et alii (2002), utilizando como variável dependente o ranking da FIFA, encontraram o mesmo formato de "U invertido" para o PIB per capita. 


\section{Referências bibliográficas}

AIDAR, A.C.K.; LEONCINI, M.P.; OLIVEIRA, J.J. de (orgs). A nova gestão do futebol. Rio de Janeiro, FGV-Editora, 2002. (2 $2^{\text {a }}$ edição).

ÂNGELO, C.F.; SOUZA, F.A.P. de. Economics of Sports: The Market Structure of Football Players and the Competitive Balance Among the Teams Before and After the Bosman Ruling . (mimeo), March/2003.

AZZONI, C. Concentração regional e dispersão das rendas per capita estaduais: análise a partir de séries históricas estaduais de PIB, 1939-1995. Estudos Econômicos. V.27, n.3, 1997.

BAUMOL, W; BOWEN, W. Performing Arts - The Economic Dilemma. New York: Twentieth Century Fund, 1966.

BELLOS, A. Futebol: The Brazilian Way of Life. New York: Bloomsbury, 2002.

CD-ROM Banco de Dados Placar. 2003. Editora Abril.

CHIAPPORI, P.A.; LEVITT, S.; GROSECLOSE, T. (2002). Testing Mixed- Strategy Equilibria when Players are Heterogeneous: The Case of Penalty Kicks in Soccer. American Economic Review, v. 92, 2002.

GAVIRIA, A. Is Soccer Dying? A Time Series Approach. Applied Economics Letters, v. 7(4), 2000.

GOEREE, J.; MINKMAN, M. The Demand for Soccer. (mimeo), 1996.

GREENE, W. The Behavior of the Fixed Effects Estimator in Nonlinear Models. Department of Economics, New York University, 2002.

HAAS, D.J. Technical Efficiency in the Major League Soccer. Joumal of Sports Economics, 4(3), 2003.

HOFFMAN, R.; GING, L.C.; RAMASAMY, B. The Socio-Economic Determinants of International Soccer Performance. Journal of Applied Economics. V. 5, n.2, Nov/2002, pp: 253-72.

HONORE, B.E. Non-Linear Models with Panel Data. CWP13/02, The Institute for Fiscal Studies, UCL, 2002.

OLSON JR., M. The Rise and Decline of Nations: Economic Growth, Stagflation, and Social Rigidities. Yale University Press, 1982.

PALOMINO, F.; RIGOTTI, L.; RUSTICHINI. A. SKILL, Strategy, and Passion: an Empirical Analysis of Soccer. Econometric Society World Congress, 2000.

Placar. Anuário Placar 2004. São Paulo. Editora Abril, 2004.

PRESTON, I; SZYMANSKI, S. Racial Discrimination in English Footbal. Scottish Journal of Political Economy, v.47, n.4, Sep/2000.

ROSEN, S.; SANDERSON, A. Labor markets in professional sports. NBER Working Paper \#7573, Feb/2000.

ROTTENBERG S 1956 The baseball players' labor market. Journal of Political Economy 64: 242-58.

SACHS, J.D. (2001). Tropical Underdevelopment. NBER Working Paper \# 8119.

SCULLY, G.W., "Sports". The Concise Encyclopedia of Economics. Indianapolis: Liberty Fund, Inc., ed. David R. Henderson, 2002. [Online] http://www.econlib.org/library/Enc/ Sports.html. (data de acesso: 24.09.2003) 
SOUZA, F.A.P. de. Um estudo sobre a demanda por jogos de futebol nos estádios brasileiros. Dissertação de mestrado. FEA/USP, 2004. [online] http://www.teses.usp.br/teses/ disponiveis/12/12139/tde-21072004-151604/publico/futebol.pdf (data de acesso: 04.08.2004) SZYMANSKI, S. Income inequality, competitive balance and the attractiveness of team sports: some evidence and a natural experiment from English soccer. The Economic Journal, v.111, Feb/2001.

The Economist. Passion, pride and profit - a survey of football. The Economist, June, $1^{\text {st }}$, 2002.

TOLLISON, R.D., "Sportometrics". The Concise Encyclopedia of Economics. Indianapolis: Liberty Fund, Inc., ed. David R. Henderson, 2002. [Online] http://www.econlib.org/ibrary/ Enc/Sportometrics.html. (data de acesso: 24.09.2003)

UNZELTE, C. O liuro de ouro do futebol. São Paulo: Ediouro, 2002.

WINKELMANN, L; WINKELMANN, R. Why Are the Unemployed So Unhappy? Evidence from Panel Data. Economica, v.65, 1998.

ZIMBALIST, A. The Economics of Sport I 8 II. In: Mark Blaug (Ed.). The International Library of Critical Writings in Economics. Edward Elgar, 2001. 


\section{Anexo Estatístico A}

Estatísticas Descritivas das Variáveis Utilizadas.

\begin{tabular}{|rrrrrr|}
\hline Correl & Obs & Média & Desv. Pad & Min & Max \\
final1 | & 560 & .05 & .2181398 & 0 & 1 \\
fina12 | & 560 & .0857143 & .280192 & 0 & 1 \\
fina13 | & 560 & .1267857 & 3330303 & 0 & 1 \\
final4 | & 560 & .1607143 & .3675956 & 0 & 1 \\
final5 | & 560 & .1785714 & .3833355 & 0 & 1 \\
pibpc | & 560 & 4.856137 & 2.811468 & -9476181 & 12.93469 \\
timeabs | & 560 & 73.75 & 12.05807 & 40 & 103 \\
art | & 560 & .0571429 & .2323229 & 0 & 1 \\
equip | & 560 & 5 & 6.184814 & 0 & 40 \\
\hline
\end{tabular}

Fonte: Elaboração dos Autores.

Correlações Bivariadas entre as Variáveis Utilizadas.

\begin{tabular}{|ccccccccc|}
\hline Correl $\mid$ & final1 & final2 & final3 & final4 & final5 & pibpc & timeabs & equip \\
final1 | & 1.0000 & & & & & \\
final2 | & 0.7493 & 1.0000 & & & & & \\
final3 | & 0.5774 & 0.7652 & 1.0000 & & & & & \\
final4 | & 0.5020 & 0.6650 & 0.8708 & 1.0000 & & & & \\
final5 | & 0.4706 & 0.6234 & 0.8172 & 0.9258 & 1.0000 & & \\
pibpc | & 0.3621 & 0.4687 & 0.5222 & 0.5542 & 0.5559 & 1.0000 & & 1.0000 \\
timeabs | & 0.2170 & 0.2616 & 0.2783 & 0.3005 & 0.3054 & 0.5008 & 1.0000 \\
equip | & 0.4319 & 0.5830 & 0.6027 & 0.6274 & 0.6299 & 0.6683 & 0.3984 & 1.0000 \\
art | & 0.5436 & 0.5017 & 0.4149 & 0.4160 & 0.4075 & 0.3453 & 0.2050 & 0.4291 \\
\hline
\end{tabular}

Fonte: Elaboração dos Autores. 


\section{Anexo Estatístico B}

\section{Testes de Hausman}

hausman fixed (Ex) logit (10) - dependent variable: finall

\begin{tabular}{|c|c|c|c|c|}
\hline I & (b) & (B) & $(b-B)$ & sqrt (diag (V_b--V_B) \\
\hline I & $\mathrm{Ex}_{\mathrm{x}}$ & 10 & Difference & S.E. \\
\hline piboc & 583334 & 9812707 & -.3979367 & 8554878 \\
\hline pibpc2 1 & -.0270015 & .0506763 & .0236747 & .0416536 \\
\hline timeabs | & 0463623 & .0003164 & -0466787 & .0444029 \\
\hline equip | & .0726953 & .0889626 & -0162672 & .0451195 \\
\hline $\operatorname{art} \mid$ & 2.34736 & 2.69299 & -.3456304 & \\
\hline
\end{tabular}

Test: Ho: difference in coefficients not systematic

$$
\begin{aligned}
\operatorname{chi} 2(5)= & (b-B) \cdot\left[\left(V_{-} b-V_{-} B\right) \wedge(-1)\right](b-B) \\
= & 3.45 \\
\text { Prob>chi2 }= & 0.6311
\end{aligned}
$$

hausman fixed (Ex2) logit (10) - dependent variable: final2

$$
\begin{aligned}
\operatorname{chi} 2(5) & =(b-B) \cdot\left[\left(V_{-} b-V_{-} B\right) \cdot(-1)\right](b-B) \\
& = \\
& 18.30
\end{aligned}
$$

Prob $>$ chi2 $=\quad 0.0026$

hausman fixed ( $E \times 3$ ) logit (lo) - dependent variable: final3

$$
\begin{aligned}
\operatorname{chi2}(5) & =(b-B) \cdot\left[\left(V_{-} b-V_{-} B\right) \cdot(-1)\right](b-B) \\
& = \\
& 85.98
\end{aligned}
$$

Prob $>$ chi2 $=0.0000$

hausman fixed (fx4) logit (10) - dependent variable: final4

$$
\begin{aligned}
\operatorname{chi2}(5) & =(b-B) \cdot\left[\left(V_{-} b-V_{-} B\right) \cdot(-1)\right](b-B) \\
& = \\
& 75 \ldots 15
\end{aligned}
$$

Prob $>$ chi2 $=\quad 0.0000$

hausman fixed (fx5) logit (10) - dependent variable: fina15

$$
\begin{aligned}
\operatorname{chi} 2(5)= & (b-B) \cdot\left[\left(V_{-} b-V_{-} B\right) \cdot(-I)\right](b-B) \\
= & 82.82 \\
\text { Prob }>\operatorname{chi} 2= & 0.0000
\end{aligned}
$$

